\title{
DADOS FENOLÓGICOS DE 10 ESPÉCIES ARBÓREAS DE UMA ÁREA DE CAATINGA (ALAGOINHA-PE) (1)
}

\author{
Dilosa Carvalho de Alencar Barbosa (2) \\ José Luiz de Hamburgo Alves (2) \\ Severino de Monte Prazeres (2) \\ Astenilsen M. Azevedo Paiva (3)
}

\begin{abstract}
RESUMO - Foram efetuados estudos fenológicos de 10 espécies arbóreas de valor econômico, ocorrentes em uma área de caatinga (Alagoinha-PE). Durante 6 anos (1982 a 1988) observaçōes fenológicas foram realizadas, porém o ano de 1986 foi considerado como ponto de referência para a análise, com registro de observaçōes fenológicas, mensalmente. Analisaram-se as fenofases de queda foliar, formação de novas folhas, floraçâo e frutificação, utilizando-se 3 indivíduos de cada espécie selecionada. As espécies estudadas apresentaram quanto aos aspectos fenológicos 2 grupos de comportamento: perenes, com substituiçäo de novas folhas do início para o final do período seco e floraçăo apenas no períudo chuvoso, exceto Ziziphus joazeiro Mart. que floresceu no final do período seco (dezembro). Decíduas, queda foliar, no intervalo de 1 a 3 meses, no final do período seco; 2 espécies floresceram no período seco (folhas novas e floração quase simultâneas); 2 espécies floresceram no período chuvoso (folhas novas e floração em etapas distintas) e 2 espécies (Aspidosperma pyrifolium Mart. e Caesalpinia pyramidalis Tul.) obtiveram 2 picos de floração em cada período, com formação de novas folhas de imediato. Quanto à frutificação 7 das 10 espécies, frutificaram no final do período seco para o início das chuvas, as demais no período chuvoso.
\end{abstract}

Palavras-chave: caatinga, fenologia, fenofases vegetativa e reprodutiva.

ABSTRACT - Phenological studies were carried out on 10 tree species of economical value occurring in a caatinga area (Alagoinha-PE). The observations were made over a period of 6 years (1982 to 1988), but 1986 was considered as the reference point for the analysis, when monthly phenological records were made. The phenophases of leaf fall, new leaf formation, flowering and fruiting were analyzed using 3 individuals per selected species. The species studied were divided into two groups in terms of phenological behavior: evergreens with leaf replacement from the beginning to the end of the dry season and flowering only

(1) Trabalho realizado com apoio financeiro do CNPq.

(2) Departamento de Botânica, Centro de Ciências Biológicas, UFPE, Recife. Av. Prof. Moraes Rego, s/n. CEP 50739, PE.

(3) Pós-graduanda do Depto. de Botânica, UFPE. 
during the rainy season, except for Ziziphus joazeiro Mart. which flowered at the end of the dry season (December). Deciduos trees casting leaves over a period of 1 to 3 months ot the end of the dry season; 2 species flowered during the dry season (new leaves and flowering occurring almost simultaneously); 2 species flowered during the rainy season (new leaves and flowering occurring at different times), and 2 species (Aspidosperma pyrifolium Mart. and Caesalpinia pyramidalis Tul.) showed two flowering peaks during each season, with immediate formation of new leaves. Seven of the 10 species studied produced fruits from the end of the dry season to the beginning of the rainy season, and the remaining ones produced fruit during the rainy season.

Key worlds: caatinga, phenology, vegetative and reproductive phenophases.

\section{Introdução}

Há várias publicações sobre a fenologia de espécies florestais, notadamente de espécies de florestas tropicais secas (ALVIM, 1964; DAUBEMIRE, 1972; FRANKIE et al., 1974; BARROS e CALDAS, 1980; REICH e BORCHERT, 1984; MEDINA et al., 1985; DUTRA, 1987), entre outros.

Sobre as plantas das caatingas, do Nordeste brasileiro, existem alguns trabalhos esparsos sobre taxonomia e fitogeografia, que se referem a aspectos fenológicos deste tipo de vegetação (LÖEFGREN, 1910; LUETZELBURG, 1922-23; ALVIM, 1949; BRAGA, 1953; ANDRADE-LIMA, 1954, 1960, 1981; TIGRE, 1968; RIZZINI, 1979; CESTARO et al., 1989).

Neste trabalho são apresentados dados fenológicos de 10 espécies arbóreas de uma área de caatinga, em Alagoinha (PE). Tais espécies são características e reconhecidamente de valor econômico e utilitário para a região, do ponto de vista madeireiro, alimentício, medicinal e outros.

\section{Metodologia}

Há seis anos (1982 a 1988) vêm sendo realizadas observações fenológicas, quanto à queda foliar, formação de novas folhas, floração e frutificação de diversas espécies arbóreas, características das caatingas, na área em estudo.

O ano de 1986 foi considerado como ponto de referência para a análise, porquanto registro de observações fenológicas foi efetuado mensalmente.

Selecionaram-se 10 espécies arbóreas, distribuídas em 6 famílias, 2 subfamílias e 10 gêneros, com 3 indivíduos por espécie.

A escolha destas espécies foi baseada em sua maior representatividade, na área.

O quadro geral das fenofases foi elaborado de acordo com SCHENNIKOW (1932), modificado segundo FALCÃO E LLERAS (1980). Neste quadro cada espécie é representada por 2 faixas; a inferior corresponde ao desenvolvimento vegetativo e a superior ao reprodutivo.

As fenofases (queda foliar, surgimento de novas folhas, floração e frutificação) foram estimadas levando em consideração os períodos de maior intensi- 
dade de cada fenofase.

As exsicatas foram depositadas no Herbário UFP (Universidade Federal de Pernambuco) e o nome das espécies figuram ao lado do quadro das fenofases.

\section{Material e Métodos}

- Área em estudo

O trabalho em questão foi realizado em uma área de caatinga do Município de Alagoinha-PE, com cerca de 8 hectares, nas coordenadas $8^{\circ} 27^{\prime}$ lat. S e $36^{\circ} 46^{\prime}$ long. W, 762m (Divisão de Cartografia da Superintendência do Desenvolvimento do Nordeste - SUDENE).

O clima da região é do tipo semi-árido quente (BS s'h') segundo KÖEPPEN.

Construiu-se um diagrama climático, segundo WALTER e LIETH (1967) com dados de 10 anos (1974-1983) fornecidos pelo 3을 Distrito de Meteorologia do Instituto Nacional de Meteorologia (MA), observados no Posto mais próximo (Pesqueira-PE) distante a $15 \mathrm{Km}$ do local.

O clima corresponde ao úpo II de WALTER (1971), ou seja, clima tropical com chuvas de verão, temperatura média de $22,7^{\circ} \mathrm{C}$ (Figura 1).

Os dados pluviométricos de Alagoinha correspondentes ao período de estudo, foram fornecidos pelo Banco de Dados Hidroclimatológicos do Nordeste - Sistema de Pluviometria (SUDENE). O Posto em questão dista $5 \mathrm{Km}$ do Sítio Riacho ( $8^{\circ} 29^{\prime}$ lat. S e $36^{\circ} 49^{\prime}$ long. W) $762 \mathrm{~m}$ de altitude.

O solo se enquadra na associação de Litólicos Eutróficos com A fraco textura arenosa e/ou média pedregosa e Podzólico vermelho (JACOMINE et al., 1973).

A vegetação se aproxima do tipo discutido por EGLER (1951), como sendo "caatinga arbustiva densa", diferindo, no entanto, pela presença de elementos arbóreos esparsos.

\section{Resultados}

A Figura 1 representa o diagrama climático da região. Pode-se observar que a maior precipitação se concentra nos meses de fevereiro, março e abril, enquanto que, o período de seca corresponde aos meses de setembro a dezembro.

Na parte superior da Figura 2, está registrada a precipitação diária, no ano de 1986. Verificou-se que o total anual de precipitação foi da ordem de 677,2 mm distribuídas, irregularmente, havendo ocasiões em que, choveu um total de $138,5 \mathrm{~mm}$ em um só dia, sendo a precipitação do mês. Na parte inferior (Figura 2) estão representadas as diferentes fenofases das 10 espécies estudadas.

A queda total das folhas ocorreu, gradativamente de 1 a 3 meses, apenas em 6 espécies, durante a estação seca (outubro a dezembro), assim distribuídas: 
Spondias tuberosa Arr. Cam. (Anacardiaceae), Cassia excelsa Schrad. (Leguminosae-Caesalpinoideae), Astronium urundeuva Engl. (Anacardiaceae), Caesalpinia pyramidalis Tul. (Leguminosae-Caesalpinoideae) e Anadenanthera macrocarpa (Benth.) Brenan (Leguminosae-Mimosoideae).

Nestas 6 espécies a formação de novas folhas e floração se processaram de 3 maneiras:

1) Queda de folhas, no final do período seco (dezembro) com floração e formação de novas folhas quase de imediato, podendo esta última se estender até o início do período chuvoso (janeiro), fato registrado com as espécies Spondias tuberosa Arr. Cam. e Astronium urundeuva Engl. ambas, Anacardiaceae.

2) Queda das folhas também no final do período seco (dezembro) com formação de novas folhas no início das chuvas (janeiro) para só ocorrer a floração na estação chuvosa (abril e maio), exemplos podem ser citados com as espécies: Anadenanthera macrocarpa (Benth.) Brenan e Cassia excelsa Schrad., ambas Leguminosae.

3) Queda das folhas na estação seca (setembro a dezembro), surgimento imediato de folhas novas e dois períodos de floração, o primeiro no período chuvoso e o segundo no período seco, fato ocorrido com as espécies Caesalpinia pyramidalis Tul. (Leguminosae) e Aspidosperma pyrifolium Mart. (Apocynaceae).

Nas quatro (4) espécies que permaneceram com folhas, Schinopsis brasiliensis Engl. (Anacardiaceae), Bumelia sartorum Mart. (Sapotaceae), Maytenus rigida Mart. (Celastraceae) e Ziziphus joazeiro Mart. (Rhamnaceae) o comportamento foi o seguinte: a floração se processou no período chuvoso, ocorrendo a formação de novas folhas no final do período chuvoso e início do período seco, exceto Ziziphus joazeiro Mart. que formou novas folhas e floresceu no final do período seco (dezembro), semelhante ao que ocorreu com Spondias tuberosa Arr. Cam. (decídua).

Quanto à frutificação observou-se que 7 das 10 espécies, frutificaram, praticamente, do final do período seco para o início do chuvoso, as demais no período chuvoso.

\section{Discussão e Conclusōes}

Trabalhos esparsos de dados fenológicos de plantas das caatingas, podem ser referidos na literatura: (LUETZELBURG, 1922-23; ANDRADE-LIMA, 1954, 1960 e 1981; BRAGA, 1953; TIGRE, 1968 e CESTARO et al., 1989) entre outros. No entanto, informações sistemáticas sobre fenofases (vegetativa e reprodutiva) principalmente de espécies arbóreas, são praticamente inexistentes.

CESTARO et. al. (1989), caracterizando algumas espécies arbustivoarbóreas de caatinga do Seridó ( $\mathrm{RN})$, constataram que o desenvolvimento vegetativo e reprodutivo das espécies com que trabalharam, dentre elas Caesalpinia pyramidalis Tul. e Aspidosperma pyrifolium Mart. ocorreu durante o período 
chuvoso na região (janeiro-julho). Nas espécies tratadas neste trabalho, observou-se que a queda foliar se processou no final da estação seca (dezembro) e a formação de novas folhas de início a meados da estação chuvosa. Quanto à floração, dois picos foram registrados, nas estações chuvosa e seca.

DUTRA (1987), realizando trabalho semelhante, abrangendo dez espécies arbóreas de cerrado (Brasília-DF), constatou que o período de maior queda foliar ocorreu nos meses de menor precipitação (junho, julho, agosto e setembro), acrescentando que o período de floração variou de espécie para espécie, processando-se normalmente no início e durante o período de chuvas, e quanto a frutos maduros e/ou secos foram constatados de dezembro a maio.

Neste trabalho considerou-se dois grupos de plantas quanto à permanência ou queda foliar. No primeiro grupo, isto é, plantas que perdem as folhas, este fenômeno coincidiu com o mesmo período referido por DUTRA (1987), ou seja, durante os meses de menor precipitação (setembro a dezembro). No segundo grupo, ou seja, plantas que permaneceram com as folhas, há uma substituição simultânea de folhas velhas por novas, especialmente durante o período seco. Com vista à floração verificou-se que esta ocorre tanto na estação seca quanto na chuvosa, podendo até formarem-se grupos distintos, como é o caso de: Spondias tuberosa Arr. Cam. e Astronium urundeuva Engl. e Ziziphus joazeiro Mart. (período seco) e Anadenanthera macrocarpa (Benth.) Brenan, Cassia excelsa Schrad., Schinopsis brasiliensis Engl., Bumelia sartorum Mart. e Maytenus rigida Mart. (período chuvoso). A frutificação das espécies analisadas, verifica-se em sua maioria no final do período seco para o início do chuvoso.

Dados semelhantes aos de DUTRA (1987) foram também constatados por BARROS e CALDAS (1980), que trabalharam com 55 árvores, da mesma região.

Por outro lado, ALVIM (1964) estudou uma série de fatores que podem influenciar nos processos fisiológicos, salientando intensidade de radiação foliar, comprimento do dia, alternância de períodos secos e úmidos e número de horas de insolação, que refletem na resposta dos processos fenológicos, tais como queda foliar, crescimento de câmbio e foliar.

MEDINA et al. (1985), analisando aspectos fenológicos de plantas lenhosas de regiões árida e semi-áridas tropicais (Venezuela), conseguiram distinguir 2 tipos de comportamento: plantas decíduas (duração foliar de 6-9 meses) e perenifólias (duração foliar de 12-14 meses) e verificaram a formação de folhas novas nas perenifólias de meados ao final da época chuvosa, enquanto nas decíduas a queda foliar ocorreu no final das chuvas, porém, novas folhas se formaram no período seco, indicando ritmos endógenos. $\mathrm{Na}$ análise realizada neste trabalho, pôde-se observar também 2 grupos: perenifólia, em que as folhas permanecem tanto nos períodos seco e chuvoso, havendo entretanto, substituição simultânea de novas folhas, no fim do período seco, e decíduas, quando a queda se dá durante a estação seca e novas folhas se formam no final do período seco para o início do chuvoso, e ainda, algumas intermediárias (Bumelia sartorum Mart.).

As análises procedidas neste trabalho estão, em parte, de acordo com as 
conclusões de FRANKIE et al. (1974), os quais verificaram em áreas de florestas secas da Costa Rica, que a maior queda foliar coincide, com o período mais longo de seca, enquanto que a floração ocorreu em 2 picos: um no período de seca mais extensa e outro no início da estação chuvosa.

REICH e BORCHERT (1984), trabalhando com estresse hídrico e fenologia de 12 espécies arbóreas, dentre estas Astronium graveolens Jacq., Bursera simaruba (L.) Sarg., Enterolobium cyclocarpum (Jacq.) Griseb, Spondias purpurea L. e Tabebuia rosea (Bertol.) DC., em florestas secas da Costa Rica, verificaram que a mudança foliar ocorre no início do período seco, e enrugamento do caule de Spondias purpurea L. por déficit hídrico. Comportamento semelhante foi constatado em Aspidosperma pyrifolium Mart. no trabalho ora realizado.

Finalmente, pode-se concluir que as espécies estudadas, de acordo com seu comportamento, formam dois grupos: perenes, com mudanças de folhas do início para o final da estação seca e floração apenas na estação chuvosa, observando-se que Ziziphus joazeiro Mart. floresceu na estação seca. Decíduas apresentaram dois comportamentos, quando à perda de folhas e floração. No primeiro, houve queda de folhas, floração e formação de novas folhas de imediato, no final da estação seca. Na segunda, o processo foi gradativo, queda de folhas (estação seca), formação de folhas novas (início da estação chuvosa) e floração no período de maior intensidade das chuvas.

Pode-se dizer que das 10 espécies consideradas, $50 \%$ florescem no período chuvoso, $30 \%$ no período seco e $20 \%$ tanto no período chuvoso quanto no período seco.

\section{Referências Bibliográficas}

ALVIM, P. T. 1949. Observações ecológicas sobre a flora da região semi-árida do Nordeste. Ceres, 8(44): 105-11.

— 1964. Periodicidade do crescimento das árvores em climas tropicais. In. Anais Congresso Nacional Botânica, 15\%, Porto Alegre.

ANDRADE-LIMA, D. 1954. Contribution to the study of the flora of Pernambuco. Mon. no $1,154 \mathrm{p}$.

- 1960. Estudos fitogeográficos do Estado de Pernambuco. Arq. Inst. Pesq. Agron., 5: $305-41$.

- 1981. The caatingas dominium. Rev. Brasil. Bot., 4: 149-63.

BARROS, M. A. G. \& CALDAS, L. S. 1980. Acompanhamento de eventos fenológicos apresentados por cinco gêneros nativos do Cerrado (Brasília-DF). Brasil Florestal n42, abr./maio/jun.: 9-13.

BRAGA, R. 1953. Plantas do Nordeste, especialmente do Ceará. Centro de Divulgação Universitária. Publ. no 2, Sér. 1. Estudos e Ensaios, Fortaleza, Ceará, 523p.

CESTARO, L. A.; LIMA, G. F. C.: FREITAS, M. E. \& FREITAS, J. D. O. 1989. Caracterização fenológica de algumas espécies arbustivo-arbóreas da Caatinga do Seridó Norte-Rio-Grandense. In: Anais Congresso Nacional Botânica. 40․, Cuiabá.

DAUBENMIRE, R. 1972. Phenological and other characteristics of tropical semi-deciduos forest in NORTH-WESTERN Costa Rica. Ecology, 6O(1): 147-70. 
DUTRA, R. C. 1987. Fenologia de dez espécies arbóreas nativas do cerrado de BrasiliaDF. Brasil Florestal, no 62, out/nov/dez: 23-41.

EGLER, W. A. 1951. Contribuição ao estudo da caatinga pernambucana. Revta. Bras. Geogr., 13(4): 577-90.

FRANKIE, G. W.; BAKER, H. G. \& OPLER, P. A. 1974. Comparative phenological studies of trees in tropical wet and dry forests in the Lowlands of Costa Rica. J. Ecol., 62(3): 881-913.

FALCÃO, M. A. \& LLERA, E. 1980. Aspectos fenológicos, ecológicos e de produtividade do Mapati (Pouroma cecropiifolia Mart.). Acta Amazonica, 10(4): 711-24.

JACOMINE, P. K. T.; CAVAlCANTE, A. C.; BURGOS, N.; PESSOA, S. C. P. \& SILVEIRA, C. O. 1973. Levantamento Exploratório - Reconhecimento de Solos do Estado de Pernambuco. Recife. v.1. 359. Boletim Técnico, 26 (Série Pedologia, nº 14).

LARCHER, W. 1980. Physiological Plant Ecology. 2.ed. Springer-Verlag. Berlin Heidelberg. New York. 303p.

LOEFGREN, A. 1910. Notas Botânicas -Ceará. Rio de Janeiro, Insp. Obr. c/ Secas. Publ. 2. Sér. I-A. 35p.

LUETZELBURG, P. von. 1922-23. Estudo botânico do Nordeste. Rio de Janeiro, Insp. Obr. c/ Secas, Publ. 57, Sér. I-A. e. V. 130p.

MEDINA, E.; OLIVARES, E. \& MARIN, D. 1985. Ecophysiological adaptations in the use of water and nutrients ny woody plants of arid and semi-arid tropical regions. Simposium Medio Ambiente, 7(2): 91-102.

REICH, P. B. \& BORCHERT, R. 1984. Water stress and tree phenology in a tropical dry forest in the Lowlands of Costa Rica. J. Ecol., 72: 61-74.

SCHENNIKOW, A. P. 1932. In: Handbuch der biologischen Arbeitsmethodem. Abderhalden, E. (ed.), v. 11, p. 251-66. Berlin: Springer. Apud LARCHER, 1980.

TIGRE, C. B. 1968. Silvicultura para as matas xerófilas. Publ. no 225, Sér. I-A. Minist. Interior Depto. Nac. Obr. c/ Secas. Fortaleza. Ceará, 176p.

WALTER, F. W. \& LIETH, H. 1967. Klimadiagramm-Weltatlas Jena. Gustav Fisher Verlag. Apud. WALTER, 1971.

— 1971. Ecology of Tropical and Subtropical Vegetation. Eidenburg. Oliver \& Body. 539p. 


\section{PESQUEIRA $(650 \mathrm{~m})$}

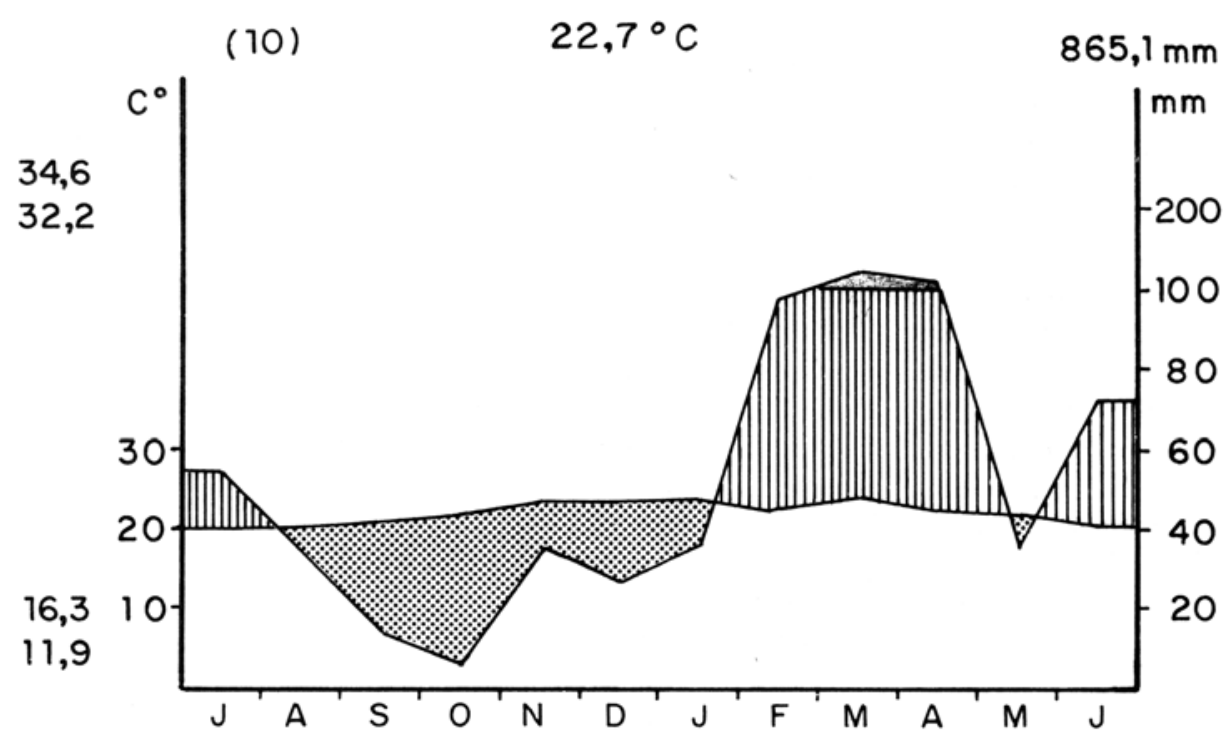

Figura 1 - Diagrama clımático de Pesqueira-Pernambuco.

(Estaçāo de Pesqueira, Lat. $08^{\circ} 24^{\prime} \mathrm{S}$, Long. $36^{\circ} 46^{\prime} \mathrm{W}$, construido segundo WALTER e LIETH (1967).

Figura 1 - Diagrama climático de Pesqueira-Pernambuco. (Estação de Pesqueira. lat. $08^{\circ} 24$ S. Long. $36^{\circ} 46^{\circ} \mathrm{W}$. construído segundo WALTER e LIETH (1967). 

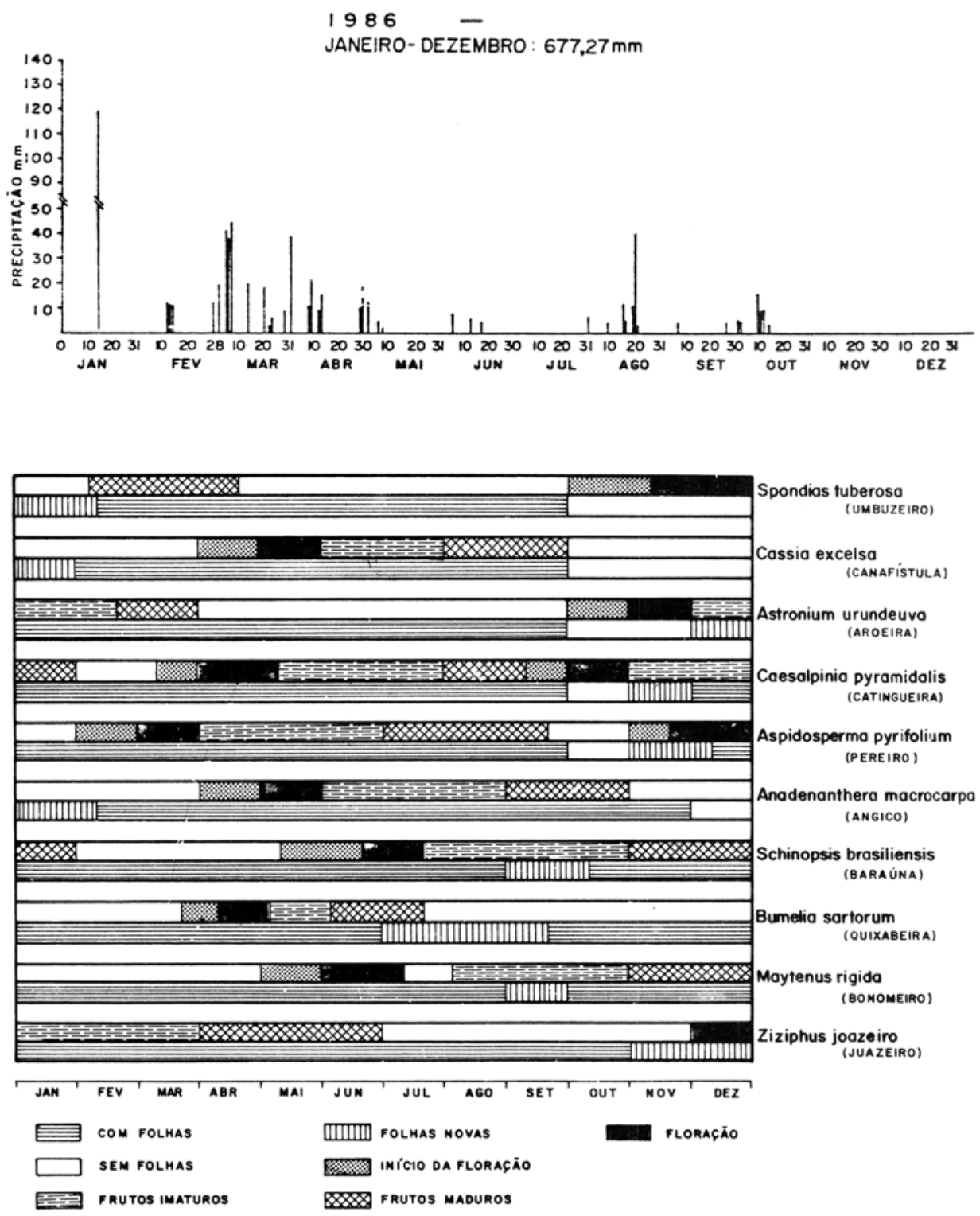

Figura 2 - Quadro geral de floração. frutificação, produção e queda de folhas de 10 especies arbóreas da caatinga (Alagoinha PE.).

Na parte superior dados de chuva (1986) para o local de estudo, fornecidos pela Sudene. 